\title{
Costume Play and Young Adults' Socio-Economic Insertion Pathways in Japan
}

\author{
Alexis H. Truong ${ }^{1}$ - Stéphanie Gaudet ${ }^{2}$
}

Received: 9 September 2019 / Accepted: 10 February 2020 / Published online: 20 February 2020

(C) The Author(s) 2020

\begin{abstract}
This article shows how young adults' cultural practices in Japan have become a social trajectory whose study is essential to understanding the life journeys of youths. Costume play, or kosupure, is a form of popular culture mediation that facilitates young people's social integration and fosters their sense of belonging. Studying these practices helps to better understand and define the changing importance of leisure in Japan in young people's lives, in particular since the collapse of the economic bubble. Based on life stories and participant observation, we analyze the interweaving of these leisure practices and life courses. Our analysis helps to understand the symbolic and social roles of these activities in practitioners' lives in the form of three pathway types. On the professional path, young people's cultural practices open doors to employment. On the enchanted path, kosupure practices function above all in "response" to a society perceived by some young adults as "conformist". On the contingency path, these practices facilitate social insertion. To conclude, we discuss these practices as cultural mediation tools that support young people's cultural citizenship.
\end{abstract}

Keywords Cultural practices $\cdot$ Socio-economic insertion $\cdot$ Life course $\cdot$ Transition into adulthood $\cdot$ Popular culture

Electronic supplementary material The online version of this article (https://doi.org/10.1007/s41978-02000054-3) contains supplementary material, which is available to authorized users.

Alexis H. Truong

ah.truong@uottawa.ca

Stéphanie Gaudet

sgaudet@uottawa.ca

1 Department of Criminology, University of Ottawa, 120 University, Ottawa, Ontario K1N $6 \mathrm{~N} 5$, Canada

2 School of Sociological and Anthropological Studies, University of Ottawa, 120 University, Ottawa, Ontario K1N 6N5, Canada 


\section{Manuscript}

Since the end of the first decade of the new millennium, costume play, or kosupure, has become one of the Japanese cultural industry's most recognizable practices. Kosupure is the practice of "dressing up," usually as characters from popular culture and from Japanese comic books (manga) and animation (anime) in particular. Here, we use the katakana writing form of "kosupure" to refer to the general practice of dressing-up used in speech, which has come to include cosplay, the word most frequently used for dressing-up in characters of manga and anime on the international stage, event-based costume play on fashion styles (like Lolita and visual kei), as well as a variety of lesserknown practices like kigurumi (mascot costumes of dolls, robots, or animals, among others) and gijinka (the personification of objects or ideas, such as countries or train companies). ${ }^{1}$

Historically, it was cosplay that first gained popularity among manga and anime fans in Japan at the end of the 1970s and into the 1980s, helping to raise the visibility and prominence of costume play practices in general over decades. Some fans attribute the discovery or popularization of cosplay to Kotani Mari, famed science-fiction author and critic, who is said to have been among the first to dress-up in manga and anime characters at two major events - Comiket and Ashicon - in the late 1970s (Thorn 2004; Galbraith 2009). Others say it was Nobuyuki Takahashi, president of Studio Hard, who encouraged fans in Japan to adopt costume play in manga and anime events after witnessing such practices at the World Science Fiction Convention in 1984 (Winge 2006). More broadly, cosplay was also strongly associated with "otaku culture", defined by Azuma $(2009,3)$ as "those who indulge in forms of subculture strongly linked to anime, video games, computers, Sci-Fi, special effects films, anime figurines, etc." Popular appetite for such visual practices further developed with the popularization of Lolita fashion and visual kei bands like Malice-Mizer in the late 1980s and 1990s (Suzuki 2007; Atkinson 2015). Regardless of its origin, kosupure is now one of many artifacts of Japan's considerable cultural industry, which developed following the country's economic crisis in the 1990s and the 2000s, known as the "Lost Decades" (Gordon 2015). These practices are prized not only by Japanese youth, but also by young people in many industrialized countries, as the international popularity of conventions like Comic-Con clearly attests.

Kosupure practices are highly visible in Japan, due especially to numerous monthly events and its media and social network presence. For cosplay of manga and anime alone, according to sources like the popular Japanese magazine Layers and websites like Cosplayers Archive, hundreds of events were held in the Kantou region, which includes Tokyo, in February 2011 alone. Since the end of the 1990s, this new market has led to an explosion in the production and sales of fashion-, manga-, and animerelated products and services. Azuma $(2009,3)$ estimated that there were already several hundred thousand consumers of such otaku cultures in the early 2000s. In 2007, the Cure website - one dedicated to Japanese cosplay specifically - estimated that there were over 200,000 cosplayers in Japan, a number that has most assuredly augmented over the years (Galbraith 2009). The kosupure industry is so significant that even the Japanese government itself has given it economic pride of place. In this

\footnotetext{
${ }^{1}$ See Galbraith (2009) for an in-depth definition of these various types of costume play in Japan.
} 
context, Japanese youth have become actors that both produce and consume popular culture products and services.

Whether positively or negatively received in Japan, the popularity and magnitude of kosupure are such that its study is essential to any understanding of Japanese youth. Our goal here is to analyze the role of this social phenomenon in the construction of young adults' life courses. How do these cultural practices influence their pathways and participation in society? This question is rarely addressed because, on the one hand, kosupure research tends to exclusively analyze and observe what happens during costume play sessions and, on the other, life course studies interested in the social processes leading to adulthood rarely focus on cultural practices. In the latter case, studies are often limited to analysis of points of entry into and departure from academic, professional, and conjugal or parental trajectories, milestones traditionally used to signal the transition to adulthood in most Western cultures, including Japan, at least until the beginning of the Lost Decades in the 1990s (Inui 2003; Brinton 2011; Galan 2018). Once the economic crisis began, however, Japanese youth began to spend more time in school, experience precarious employment, and cohabit with parents for longer periods of time, while also delaying conjugal and parental obligations. The 2008 global economic crisis further intensified these changes.

By presenting a typology of three pathways characteristic of young kosupure practitioners, we demonstrate the role these cultural practices play in their trajectories, particularly in terms of social and professional insertion. We define kosupure as a "cultural" practice in the sense that it is intertwined with the cultural industry and its history. We show how kosupure allows young people to claim a right to be different, enables them to actively participate in a shared culture and becomes a manifestation of cultural citizenship (Turner 2001). We developed this typology from the life stories of young Japanese participants and participant observation of events held in Tokyo between March 2010 and May 2012. Our goal is to make an empirical and theoretical contribution to cultural practice analysis within life courses studies. This analysis also led us to explore a theoretical corpus that we had not developed before the completion of the fieldwork: cultural citizenship theories. Recent interpretations of these theories help elucidate the socio-professional phenomenon under study. We argue that, in the current context, practices associated with popular culture facilitate the social insertion of young adults and contribute to the development of their active citizenship.

\section{Youth, Pop Culture, and Life Course}

In modern Japanese, asobi (play) is the term most frequently used to encompass, "in addition to games and sports, also pastimes, merrymaking, diversions, pleasures, fun, leisure activities, hanging out with friends, hosting or being hosted, gambling and doing nothing" (Daliot-Bul 2009, 355). Since the beginning of the Lost Decades, play has become increasingly associated with ideas of developing one's interpersonal communication and one's well-being, as well as expressing individualism and reprivatizing one's free time (Daliot-Bul 2009, 372; see also Manzenreiter and Horne 2006). In this context, research into costume play practices has often defined them as subcultures, with an anthropological interest in shared values and Japanese youth culture. Some of this work includes analyses of costume play performances (Gin 
2011; Lamerichs 2011; Rahman et al. 2012; Scott 2015), fan communities within Japan (Okabe 2012; Lamerichs 2013), as well as exploring the links between costume play and fashion - for example, Gothic/Lolita style (Gagné 2008). Other studies aim to understand the successful development of sales and services associated with the cultural industry since the economic crisis of the 1990s (Kelts 2006; Ito \& Crutcher 2014). Such works have offered a fundamental contribution to defining the importance of studying these oft-elusive practices, including how they shape definitions of self and perspectives on gender in the changing social and economic context of contemporary Japan (Gagné 2008; 2013; Leng 2013; Truong 2013).

Outside of Japan, the study of youth culture and youths' investment in cultural practices, including those associated with popular culture, has favored two theoretical approaches. The first is the subcultures approach established by Cohen (1955) and Becker (1963) of the Chicago School and by Hall and Jefferson (1976) and Hebdige (1979) of the Centre for Contemporary Cultural Studies (CCCS), among others. The concept of subcultures generally referred to the construction of alternative systems of meaning and values in relation to a dominant culture. Of interest here is how these works have contributed to the study of resistance and social change (Bucholtz 2002). However, they have also been criticized for neglecting issues of gender and Black and Asian subcultures, for their lack of interest in "lived experiences", and for minimal use of empirical data to support their theories (Muggleton 2000; Williams 2011; Hodkinson 2012). In contrast, in Japan, the term "subculture" was originally not defined in terms of opposition between highbrow and lowbrow cultures, nor as "counterculture". Rather, its use was more akin to the idea of "postmodern culture" used outside of Japan, heavily influenced by the works of Miyadai Shinji and Ōtsuka Eiji, two renowned cultural critics who helped shape debates on these questions in Japan (Yoda 2006; Miyadai 2011).

The second broad approach emerged from recreation and leisure studies. These works first focused on the use of free time (Cushman et al. 2005), classification of leisure practices (Stebbins 1992), and more generally differences between the cultural and sports practices of various social and age groups. Because this approach focused primarily on childhood and old age, young adults are often underrepresented in studies that argue the importance and benefits of leisure, particularly in regard to play for the social development of young children (Voce 2015) and pastimes for the health of retired persons (Dupuis and Alzheimer 2008). In the context of Japan and kosupure, a notable exception to this is Gagné (2013) work on the Lolita subculture, how young women engaged and disengaged from Lolita over time, and the way this practice shaped their outlook on life and their future trajectories. Although Gagné highlighted the importance of temporality, he found that their experience was best defined as a "bracketed adolescence" on the path to "social adulthood" (Gagné's 2013, par. 41). More specifically, he helped map out the points of entry and departure from the practice. Further exploring this question of temporality appears essential to us, as emerging research on popular culture has increasingly shown how cultural or "creative" industries increasingly play a role in the way young people develop alternative careers, especially outside of more "formalised cultural industry structures" (Bennett 2018, 141).

In contrast, sociological research into Western youth rarely addresses the role or effects of cultural practices on the life courses of young adults. Instead, these studies 
have focused on the transformation of entry thresholds to adulthood with regard to employment, family, housing, and extended adolescence. More recently, a debate concerning a new period of life, "emerging adulthood", explores symbolic and identity perspectives associated with transformations at this stage of life (Arnett 2000; Gaudet 2007; Côté 2014). Culture remains in the background, interpreted as the backdrop against which young people construct their life trajectories. However, in Japan and many other post-industrial countries, cultural practices now appear to play a key role in these pathways, particularly in light of their influence on professional and romantic trajectories and the way young people define themselves.

Despite these limitations, the life course approach provides many premises and tools for studying youth cultural practices from a process-based perspective. This lens allows us to scrutinize the interplay between different types of trajectories (academic, professional, family, cultural), the significance of a trajectory over others, as well as the critical moments associated with these trajectories, as identified and understood by participants. We use the "pathway" concept to define how kosupure structures the life trajectories of young adults in Japan. Pathways are understood as well-traveled sequences of transitions that are followed by individuals and groups through society while also representing attributes of that same social system (Elder 1985; Pallas 2003, 168). The pathway concept facilitates an understanding of how these cultural practices both structure young people's life trajectories and result from broader socio-historical transformations (Elder et al. 2003; Gaudet 2013), including the Lost Decades and the Japanese government's subsequent investment in the cultural industry.

We argue that kosupure becomes a tool used by young adults to negotiate the opportunities and constraints they face in their life course or even forge alternative trajectories outside traditional norms, in a context where young people sometimes no longer have access to, or no longer wish to conform to, conventional life courses. We believe that this is a perfect example of how groups use leisure "to participate effectively, creatively and successfully within a national culture" (Turner 2001, 12), especially inside Japan's valued cultural industry. Costume play allows young Japanese people to renegotiate their identities, to reframe their socio-economic participation and to become active producers of culture in Japanese society. Recent scholarship acknowledges this phenomenon with the concept of cultural citizenship, "the right and the capacity of people to develop and pass on diverse cultural traditions and identities while participating effectively in a shared cultural and political arena" (Kuttner 2015, 70). This way of defining citizenship has been extended to its cultural dimensions to grasp the ways in which marginalized groups claim the right to be different, to propagate their identity and their lifestyles, and to express their differences. Such research promises to address novel ways of belonging and participating in society that were previously ignored in the literature. Thinking in terms of cultural citizenship further allows us to move away from dominant tropes in popular discourse, where such practices have often been understood as a withdrawal from society, rather than participation and insertion into it.

According to Miller (2007), cultural and media institutions allow citizens to participate in societal life. This definition can be expanded to include the range of daily cultural practices that create places of exchange for both dominant and alternative cultures (Poirier 2013). It seems that young people are more likely to use cultural 
practices to assume the role of citizen and participate in social and political life (Caron et al. 2018). Analyzing how they participate, with whom and for what purpose is of importance to understand how culture helps to construct their sense of belonging and how it gives meaning to their lives. As we will see, for many youths, kosupure has become a gateway for them to engage in recognized and valued forms of social participation. As Stevenson (1997) explains, cultural citizenship helps us understand how "society makes commonly available the semiotic material cultures necessary in order to make social life meaningful, critique practices of domination, and to allow for the recognition of difference under conditions of tolerance and mutual respect" (42). It is therefore necessary to redefine the significance and role of cultural practices in young people's lives: more than just hobbies, these practices can become a vector for social insertion through which young adults join society and participate in its construction.

\section{Method}

Our analyses focus on the life stories of ten participants collected through repeated semi-directed interviews, life history calendars, and broader participant observation. Participant observation with these participants and others was conducted in hundreds of events in Tokyo and its surrounding areas. This included events that focused on photography, dance, themed parties and other commercial ventures, like the Tokyo Game Show, where costuming had been allowed and was sometimes encouraged (Truong 2016). ${ }^{2}$ Participant observation also included preparing for events as a group and the somewhat common practice of spending time after events in order to share photographs and discuss our experience. For each main participant, interviews were conducted over many months, going to events as a group in between each interview.

Combining repeated interviews and participant observation is a method we developed in order to explore the diachronic dimension of participants' experiences through their life stories and link them to its synchronic dimension, discussing the data that we had collected during participant observation with participants in subsequent interviews (Truong and Gaudet, forthcoming). Using narratives constructed through several retrospective interviews is an ideal method to understand individual processes through time (Thomson and Holland 2003), highlighting the reflexivity of interviewees on critical moments of their life course, especially in a life course approach. It also contributes by facilitating reflections on the place of temporality in the understanding of social phenomena and the development of tools to apprehend it (Thomson and McLeod 2015). Finally, Cohler and Hostetler's have also shown how life stories are a valuable methodological tool to understand the "structure and meaning of adult lives" (Cohler and Hostetler 2003, 556).

Fieldwork took place in Tokyo, Japan, between March 2010 and May 2012. Although the fieldwork was continuous, it was interrupted following the March 11th Tohoku earthquake and resumed a month later. For the main interviews, we selected participants who came of age at different points in time after the beginning of the

\footnotetext{
${ }^{2}$ The interviews and the participant observation were conducted by A. H. Truong. Most interactions were conducted in Japanese, while some were conducted in part or in whole in English, if and when participants wished to express themselves in that particular language.
} 
economic crisis in Japan and who had a long history of costume play. Interviews were used to obtain an emic perspective: participants were asked about their kosupure experiences, while the narrative form of the interviews shed light on the interviewees' process and purpose of these practices in their lives (Dubar 1998; Demazière and Dubar 2004). Data concerning the objective timelines of participants' family, academic, professional, leisure, and other trajectories (Dubar 1998) were collected from participant-created life history calendars. Observable information about interactions, performances, and self-presentation was collected from participant observation during kosupure events. Vertical analysis of three interviews per participant (Gaudet and Robert 2018) was performed to identify the "plot" of each narrative (Demazière and Dubar 2004). The goal was not simply to "discover" codes to define each category, but to "reconstruct" the code that organizes these categories according to previous trajectories, understandings of the current situation, and more or less probable futures (Demazière and Dubar 2004, 99). Using an iterative process, a generalized theory was built from analytical categories developed from interview transcripts, calendars, and observations in order to better understand and compare the life course of each participant with one another.

What we present here is not a descriptive typology, but an ideal typology in the form of analytical categories that allow for a degree of generalization. These pathways were identified by focusing on specific circumstances within all of the participants' different trajectories. They emerged because they helped make sense of the role of participants' kosupure practices and, more specifically, the interweaving of their practices and life trajectories. Three types of pathway were identified: the professional path, the enchanted path, and the contingency path. Concomitantly, an in-depth analysis of each path is presented in the form of an interviewee's life story. Each narrative was chosen for its explanatory power, but has been modified to illustrate experiences shared with other participants who traveled the same pathways and to protect the confidentiality of participants.

\section{The Professional Path}

Akiko is a 27-year-old university graduate. We chose her story to represent young adults who abandoned employment valorized before the Lost Decades in order to create professional careers in areas directly related to their interests and pastimes. To earn a living, Akiko became a professional kosupure practitioner; she works, in costume, as a manager in a costume play bar, accepts contracts as a kosupure model, and organizes costume play-related events. None of these jobs are related, nor were they dependent on her university studies. One should note that, in Japan, most university graduates do not necessarily end up working in the field that they studied in, with schools' relationship with employers having been a key factor in nominating students for jobs in the post-war school-to-work education system (Kiraya and Rosenbaum 2003). However, what is interesting here is that she found this work through her contacts and extensive experience in the kosupure community, and in direct relation with her personal interests. Furthermore, it was a recognition of her skills as a costume play practitioner.

As an adolescent, Akiko had trouble making friends at school. She was teased and sometimes bullied by her peers. At 13, she discovered a Japanese comic book and 
animation store near her home and became a regular visitor. There, she met and established friendships with young people her age who shared her interests. A friend from the store invited her to her first costume play event where people were dressed as characters from their favorite series. Hoping to get to know the person better, Akiko accepted and together they prepared their costumes. This was a turning point, an entry point for Akiko, who soon became a dedicated kosupure fan.

In her interactions with other kosupure practitioners also playing their favorite characters, Akiko felt that she could "be herself". She felt valued and accepted when others complimented her costume, and particularly when they took photos. In her own words,

Of course, wearing the costumes is also great, but being asked to pose for a picture by someone, it's like that person is interested in you too, right? That made me happy. Like, people around you that see you, people you don't know that look at you and recognize the character. That kind of thing, when they come and talk to you, it's because they feel like I look like that character, isn't it? Like I'm really close to that character? That, that makes me really happy.

For Akiko, being approached by other costume players was gratifying. The fact that they recognized the character she was performing meant that they shared an interest in the same characters and series.

The particularity of kosupure, here, is that the costume worked both as a "window" into her inside world, for those who recognized and appreciated her performance, but also as an "armor", offering a feeling of protection in the face of strangers who did not (Truong 2016). Furthermore, the fact that they recognized the character also meant that they recognized her kosupure talent and her ability to play the part. She adds:

It was like it became easy to make friends. Even though I had just started. [...] Receiving compliments made me happy and, there were a lot of people who made great quality costumes around where I lived. So like, I wanted to get closer to those people, and I made great efforts. And like, having those people come and talk to me and such, that made me incredibly happy.

For the first time in her life, Akiko felt like she had "real friends" and felt included. The feeling of belonging to a group, one of citizenship's essential elements, resulted from this cultural practice. The exchange of artifacts from popular culture created opportunities to share information, experiences, and personal recognition.

Over the years, Akiko's kosupure practices allowed her to participate regularly in costume play events and develop a network of friends. Upon finishing her university studies, Akiko found full-time employment with a private company. Since the beginning of the Lost Decades, such a rapid transition from school to work has become less common in Japan. However, even though Akiko succeeded in quickly securing regular employment, she admits that she found her work life stressful. She experienced genderbased discrimination and her masculine superiors made her feel as though she was never doing enough. Akiko felt alienated at work, the activity that had traditionally been the primary social insertion tool for young adults in Japan.

When an acquaintance from the kosupure community asked her if she would like to stop working at the company to host events and work as a manager in a costume play bar, she said yes, despite the fact that she would lose the benefits associated with her regular job. For Akiko, kosupure opened the door to other professional opportunities. Her parents opposed her decision at the time and continued to reject her choice some 
years later, when we interviewed Akiko. For them, her decision was "irresponsible", and the resulting tension led Akiko to sever ties with her parents. She feels that the kosupure community, who accepts her "as she is", is her "real family". Be it at school, at work, or at home, Akiko's tastes and the way she identified with kosupure led to experiences of exclusion and, at times, marginalization and stigmatization. But Akiko is now well known in the kosupure community. She even met her romantic partner there.

Akiko's story illustrates the first type of pathway, the "professional path". Young people who follow this trajectory place kosupure at the center of their lives. Breaking into the cultural industry becomes a personal and professional life goal. This is akin to what some have called "DIY careers" (Threadgold 2018) or "creative [industries] career" (Campbell 2013), with a shared interest around redefining "what constitutes successful lives" in precarious times. Akiko's story further highlights how such phenomenon are intimately tied to fostering a sense of belongingness, not simply as a space for like-minded individuals to come together, but to challenge certain social norms that constrict the ability to express and recognize marginalized ways of being and acting. On this path, young adults discover kosupure at a time when such practices help them to overcome feelings of social isolation. They develop a feeling of belonging to a cultural group; most of their friendships and romantic relationships organize themselves around these practices. Costumed practices become their primary form of social and professional involvement. As a result, kosupure leads to other life paths through accrued participation, including educational, professional, and romantic trajectories.

Kosupure also influences how young people interpret the world around them and within which they become adults. For example, Akiko prioritizes the search for personal happiness above the job security valued by adults of her parents' generation. Kosupure also shapes young practitioners' values and transforms their definitions of success and an ideal life, shaping their outlook on their own life course. Here, the experience of young adults in the professional path did not appear as "bracketed" as what Gagné (2013) had observed in the Lolita subculture, and further extended in the future, even for participants who were in their 30s. Participants also claimed that certain things are more important for them than for their parents, including knowing and being "themselves", being happy, and surrounding themselves with close friends. Paradoxically, their values also reflect contemporary discourses on popular culture that encourage competition and make individuals responsible for their success. Her story is an illustration of how highly educated young people internalize these discourses on the importance to be "flexible, creative, self-reliant, and resilient individual managers of their own lives and careers" (Oinonen 2018, 1344; see also Galan 2018). It further shows how, from her perspective, "success" in her life no longer means "having a family and a work-oriented career" but rather becomes a search for meaning in one's life. The ability of these young people to break into the industry depends on being able to stand out from the crowd. This observed paradox supports Giddens's analysis of a desire for authenticity in the individualized world of advanced modernity (1991).

Through their involvement in kosupure events, these young people develop skills valuable in both the cultural industry and Japanese popular culture. Along this trajectory, kosupure becomes a career choice, and is described not only in terms of "hobby" (shumi) but also as "work" (shigoto) she is proud of. For Akiko, the turning point was the moment she left her regular job. Employment opportunities created by the growing cultural industry allow young people like Akiko to take a "leap of faith" towards such 
new career opportunities. As professional kosupure practitioners, these young adults also achieve a status valued by younger generations.

However, launching into a professional kosupure career can also lead them to make sacrifices. Some feel pressured to end relationships in order to pursue their new career. Others hide the fact that they have a significant other, an expectation that weighs more heavily on women. Akiko cannot be open about her romantic partner because young women practitioners are often expected to remain single and prioritize kosupure above all else. Professional investment in the practice leads others to renounce romantic relationships altogether to circumvent the obligations they associate with conjugal life and becoming a good life partner or a good parent. As kosupure creates new opportunities in their life course, it also imposes new constraints, bringing each person to reflexively consider the choices they face, or the expectations they experience as impositions. According to one participant,

$[\mathrm{m}]$ aybe, there's just too many things I want to do, and I just haven't shifted into this idea of love. And so, it's really a feeling like I'm a person who likes work very much, working, doing kosupure... Making time to meet with a boyfriend would be impossible to start with. So, isn't it alright just not having a boyfriend? Like, instead of having fun with just one person, I can meet a bunch of people, communicate, and continue to get closer to my dream.

This experience with kosupure is an example of changing gender roles and expectations in Japan, and some women's growing desire to enjoy time of their own (Nomaguchi 2006). This way of thinking was further reinforced in the case of other participants in their 30s, who saw some of their friends marry and stop practicing kosupure as they started to have children. As Nomaguchi writes, "[b]ecause women tend to be the primary caregiver of children, women are much more likely than men to end up sacrificing their personal leisure time and down time because of their child care responsibility" (2006, 1674).

By mediating relationships with popular culture artifacts, kosupure allows young adults who are often relegated to the role of consumers to produce cultural content and services. These tastes and interests, formerly sources of marginalization and stigmatization for Akiko, become a source of social and economic recognition. As Stevenson (2003), Pakulski (1997) and others maintain, a cultural understanding of citizenship forces us to reflect on what is excluded, marginalized, or made invisible in contemporary societies. Here, cultural practices such as kosupure, which were once stigmatized, help young adults overcome some of the obstacles they face. Life choices that often have been framed as a rejection of society's rules in popular discourse become a tool for them to engage in activities which have long been associated with the practice of active citizenship, namely finding employment and building their own career in the cultural industry. However, although these practices facilitate participation in society by easing social and economic insertion, positions within cultural industries are not clearly defined. Kosupure-related employment opportunities rarely offer the security or benefits associated with corporate positions. Even when young people do break into the industry and achieve significant financial success, most remain in economically precarious circumstances. The evolution of their careers will therefore depend largely on their ability to adapt to market and industry transformations over the next few decades. 


\section{The Enchanted Path}

The next case illustrates the second type of pathway. At 23 years old, Maiya is a physician who lives with her soon-to-be husband. They would like to have children. Her life trajectory corresponds exactly with social scripts that value personal and professional success as defined by her parents' generation: she is in a relationship and has regular, socially valued employment. She would be regarded by many as successfully performing the dominant and idealized representation of active Japanese citizenship. But she also leads a secret life as a kosupure practitioner. In kosupure, she has found a way to break the rules and norms of a world she sometimes finds "too conformist" and "too traditional", a world that, in her opinion, is not particularly tolerant of difference.

Although having a family is important to Maiya, the daily grind weighs heavily upon her. Kosupure satisfies a deep need to experience new and exciting things that serve to "renew her energy". During the week, Maiya gets up, goes to work, comes home, and takes care of things around the house. She sometimes works night shifts at the hospital. She enjoys her life. But each weekend, whenever she can, she secretly prepares a small suitcase and leaves for the day, and sometimes even for the night. In her suitcase, she smuggles her costumes. Neither her partner, nor her family, nor her coworkers know that she practices kosupure.

Maiya's well-paying job means that she can spend considerable amounts of money on costume play. Like Akiko, Maiya's costumes are inspired by her favorite characters. While Akiko's kosupure practices were linked to a "desire for self-transformation", allowed her to feel "more accepted" by her peers, and "transformed" her so that she might become more "herself", Maiya's experience is quite different. Maiya is interested in the "temporariness" of the performances; she wears unusual clothing to events and breaks with her daily routine. For her, costume play is primarily a way to "disconnect" and "let herself go" for a brief moment, which she says allows her to release accumulated stress. In a sense, it is Maiya's way of exploring the "gaps and loopholes" that exist in her adult life and in Japanese society, in order to engage in different ways of being or even in relative deviance (White 1993).

Unlike Akiko, who is open about her passion for kosupure, no one is aware of Maiya's double life. Maiya prefers to keep the different spheres of her life separate, as she does with her different networks of friends and acquaintances. Though Maiya had no plans to stop doing kosupure, and we met others who navigated this pathway well into their 30s and 40s, this experience of temporariness and its separation from other spheres of life is somewhat akin to the bracketed experience of Lolita practitioners defined by Gagné (2013). While Akiko experienced social exclusion outside kosupure, Maiya feels valued both at work and at home. She also has separate circles of friends outside of kosupure; her situation is therefore dissimilar from that of Akiko, whose friendships developed exclusively through kosupure. Maiya values the ability to "balance" her relationships and activities at work, at home, and in her leisure time. As Maiya explains:

I think balance is important. If you only do the things you want to do, you'll become addicted to kosupure. [...] Before exams, I'd stop doing kosupure a bit and such. Before exams, I'd control myself. Just by being patient a bit, I could hold some balance. I just set aside time to do the things I had to do that were priorities, and then I did kosupure. 
[...] Like, if I compare my career and kosupure, isn't a career more important? Make my career my priority and control myself when it comes to kosupure, just be patient a little, that's my decision.

According to Maiya, adults should prioritize work and family because they are more "important". Kosupure is but "casual leisure" (Stebbins 1992). Maiya also states that kosupure practitioners who fail to fulfill this "responsibility" should behave "more maturely". Maiya ponders whether she should perhaps stop or reduce her participation in kosupure events in the coming years, once she has had children. For her, it could be "frowned upon" and "irresponsible" for a mother to spend her free time "enjoying herself". As such, Maiya's comments contribute to the reproduction of discourses that delegitimize young people's cultural practices and participation in popular culture, if and when their practice does not fit with a more traditional understanding of leisure as secondary to work and family life.

We call this second type of pathway the "enchanted path" because it reflects its followers' desire to make sense of a generally conformist social existence focused on the personal and professional success they themselves value. Young people on this path, including Maiya, place family and professional obligations above values of personal development, such as the pursuit of happiness and self-knowledge. Contrary to young adults on the professional path, the narratives of those on the enchanted path reproduce a traditional notion of the division between work and leisure: recreational activities take place at different times and in different places than "serious" activities. It is described as a form of "playful evasion", a way to "resource the self" (Skeggs 2004). In this case, the costume continues to act as an armor, protecting the identity of the person wearing it as they engage in these practices regarded by many as atypical.

Even though it is considered uncommon for such individuals to engage in such practices that continue to be labeled as "deviant" by some, engaging in kosupure is not expressed as "resistance" for those navigating this enchanted path. Young people engaged in this pathway actively work to separate their practice from their other spheres of life. Outside of these practices, these young people present themselves as adults that follow accepted social conventions and they are usually recognized as "respectable" members of Japanese society. Kosupure operates as an "enchantment" by creating "magical" moments and spaces where these young adults can let themselves go and have intermittent "exciting", "atypical" experiences.

At the same time, thinking about this pathway in terms of cultural citizenship helps us see how these young practitioners are also critical of the very worldview and selfdefinitions whose reproduction they participate in, and which dominated Japan's social structure until the beginning of the Lost Decades in the early 1990s. Kosupure is not only an expenditure of free time: it is shaping their understanding and relation to difference, even outside of play. According to participants in the enchanted pathway, kosupure has allowed them to experience firsthand other ways of being, including what it means to be or feel different than others - something they associated with the distinctive features of costuming and performance in kosupure. Practitioners feel that they are more open-minded than the people they associate with outside the kosupure community, particularly regarding the ability to accept difference. Indeed, practicing kosupure has led to friendships with people they would otherwise never spend time with. 
Furthermore, although these young adults value the family and professional spheres, they also seek other spaces of identification and belonging. For them, conformity can sometimes be "uncomfortable". Nonetheless, they navigate between kosupure and conventional society, often by keeping them entirely separate, which allows them to avoid the kind of tension and confrontations Akiko experienced with her parents. Kosupure is also their way of periodically resisting dominant experiences and norms, including gender norms. Several young participants favored costumes of the "opposite" sex, even though they identified as cisgender, a practiced often identified as "crossplay" in the case of cosplay outside of Japan and as "josou" and "dansou" in the case of more general male to female and female to male cross-dressing costume play in Japan (Daliot-Bul 2009; Truong 2013). Kosupure allowed them to see the world from another perspective, to critique specific social imperatives, or to more readily accept ways of being and behaving labeled as deviant outside of kosupure. In this way, kosupure becomes a form of cultural mediation that provides an understanding of the Other and encourages the acceptance of difference through social inclusion.

Of the three pathways, it is the enchanted path that most reproduces traditional attitudes in Japan and the strict distinctions between leisure and "serious activities". However, although these practitioners insist that their practices are "only a hobby", in many cases, including Maiya's, participation rivals that of interviewees on the professional path. Such intensity and frequency allows them to gather a kind of "subcultural capital" valued by the community's youth (Thornton 1995). Unlike participants in the first group, investment in kosupure is not accompanied by lessened investment in other trajectories, like family or education. When time is too limited, practitioners on the enchanted path temporarily set kosupure aside. This corresponds with their assessment of the relative importance of personal and professional obligations and of the pursuit of pleasure.

\section{The Contingency Path}

Finally, Kaya's story illustrates the trajectories of young people whose pathway is characterized by tensions between social inclusion and exclusion. At the time she was interviewed, 25-year-old Kaya was seeking employment. She had completed her university studies two years prior. Before the Lost Decades, the prestige of her alma mater would have all but guaranteed regular employment after graduation. Instead, she has spent three years looking for full-time work, but has been unable to find a job. It is a challenge that many other young Japanese adults also faced, as reforms in the education system made them increasingly responsible for their own careers, in a context where graduate employment had been in regular decline until 2005 (Galan 2018). Her search for employment becomes more difficult every year as the number of graduates competing with her increases. For the moment, she still lives with her parents and depends on them for financial support. She belongs to a category of young people regularly stigmatized by the media and given a variety of negative labels, including "parasite single" and "NEET" (Not in Education, Employment, or Training") (Genda 2007; Uchida and Norasakkunkit 2015).

Kaya is socially isolated. Her lack of participation in workplace or educational environments limits her ability to meet new people. Like Akiko, Kaya discovered 
costume play as an adolescent at a time when she was having difficulty connecting with people her age. When she was younger, kosupure was the only place she felt valued, where she felt she could be herself, and where she could surround herself with friends. This has not changed. Without kosupure, Kaya says she feels "disconnected" from society. On more than one occasion, people close to her have recommended that she stop practicing kosupure in order to concentrate on finding employment. She says:

If I didn't have a reward of the, this ability of doing, to do kosupure, then I think I'll be depressed (laugh), and still cooped up in my room. Well it sort of happened this last month. I had to go to all these seminars and forums for jobs, to do like interviews and such. It was really time consuming and I hate the suits, and I hate those people, those recruit, those recruiting people's faces and such. It was really depressing. But I, I had this restraint of, that I have to do this. I have to get a job or I couldn't kosupure anymore. It felt really restraining and it was really stress, I was really stressed so...

Kaya explains that she feels judged, something she sees in the way others look a her; she also feels the weight of her circumstances. On more than one occasion, Kaya tried to stop doing kosupure to focus on finding employment. However, when Kaya stopped practicing kosupure, she ultimately cut herself off from her primary support network. In contrast to Maiya, who can simply postpone her kosupure activities, Kaya becomes isolated when she no longer participates in events, as this is where she has built the most friendships. She also loses the place where she feels most valued, where she feels recognized by her peers. Furthermore, since kosupure is the only place she feels valued, stopping her activities also exacerbates negative emotions linked to her circumstances. As Kaya's situation continued to worsen, her mother eventually encouraged her to return to kosupure so she could see her friends.

We call this type of pathway the "contingency path" because it encompasses the trajectories of young practitioners who have difficulty with socio-economic insertion and who share an apprehension towards what the future holds for them. Kaya is not alone in this, as this is an experience shared by many youths of her age group in Japan. The particularity of her situation is that we can see how kosupure indeed becomes her link to society, rather than a way for her to withdraw from it. The life plans of young adults on the contingency path are situated outside kosupure, as with Maiya and other practitioners on the enchanted path. Most of them want to find regular employment or start a family, but have yet to reach the interview or employment stage. Like Kaya, they have difficulty finding employment relevant to their education or professional training. These young people with a desire to do so also report having difficulty finding a partner to build a lasting romantic relationship with. Kosupure is their primary tool of social insertion, their way of "surviving" on the margins until they are able to "fit into society" by securing social or professional statuses traditionally valued by the generation of their parents. Their cultural practices are not always consistent with their future expectations, nor with the expectations they feel are imposed upon them. They are passionate about kosupure and spending time with friends, as well as somewhat "ashamed" of enjoying themselves at a time when they are told that they should be "serious" and focused on "making a life for themselves". Social norms are experienced simultaneously as an ideal to be achieved and a burden to bear. These elements, perhaps linked to a transitional state, contribute to the construction of participant ambivalence towards kosupure and their plans for the future. 
Another difficulty experienced on this pathway is the challenge of financing kosupure activities. To cover her expenses, Kaya leveraged her costume play experience to find part-time employment in a manga and anime store. Although she enjoys working in a field close to her interests, it does not solve all of her problems. Kosupure is expensive. Having a part-time job means she has a lot of free time, but her salary would not cover, for example, all of the costs for rent and food if she left the parental home. Sometimes, she volunteers to do kosupure in rural children's festivals around Tokyo, doing characters that are popular with those age groups. She likes seeing the positive reactions on children's faces as they recognize the characters. Here, we see how kosupure opens certain opportunities for her to actively express a cultural form of citizenship by engaging in broader cultural events, despite the challenges she is facing. Her father insists that being happy at work is not important, that she must find "serious" employment. For Kaya and many people her age, however, "liberty" is an important value. Kaya must negotiate the tension between her present situation and what she would like to accomplish in the future:

$[\mathrm{M}] \mathrm{y}$ parents, especially my dad, he tells me that, you know, there aren't true freedoms in this world. You can't really do what you want to do (laugh). [...] And, when my I want to ask my dad about it, and he said "no, there aren't true freedoms in this world, so you have to, you have to follow the rules to earn your own freedom." That's what he told me.

Kaya feels guilty about spending time and money on activities perceived as juvenile by her family, other adults, and society's dominant norms. She sees herself finding regular employment or getting married and having children, but cannot seem to meet a potential romantic partner. This is why she has been "in between" for the last two years. She is waiting. And while she waits, costume play is her most effective tool to meet people and have meaningful experiences, despite her conflicting emotions.

As Kaya's story reveals, for many young people coming of age in Japan after the beginning of the Lost Decades, economic precariousness is sometimes accompanied by social precariousness. By helping them regularly meet with friends and make new ones, kosupure allows them to participate in society and combat social isolation. Through it, they can belong to and identify with a social group. Practicing kosupure also gives them the feeling of contributing to society by holding part-time employment related to their hobby or by being part of a recreational community. The relationships these young people develop within kosupure become their primary social support network. This cultural practice is a "stabilizing" factor in their life course at a time when they feel that they have "lost their way".

\section{Discussion}

We presented an analysis of the three pathways that emerged from our corpus and a description of how these kosupure trajectories contribute to the social and professional insertion of its young adult practitioners. The significance of kosupure's role in this insertion led us to reflect on these practices in terms of cultural citizenship, a working hypothesis that emerged through inductive analysis. Specifically, practicing kosupure allows young adults to develop new attitudes, shared values, and other perspectives specific to this form of popular culture, while also creating links to their social realities 
beyond the community and its events that reframe cultural codes in Japanese culture. Participating in practices such as kosupure shapes their relationship to popular culture and the society they are maturing into and leads them to define and carve a place for themselves in terms of ideals of emancipation and social justice (Casemajor et al. 2017), especially in regard to their relation and engagement with difference through kosupure. For these young adults, developing an openness to difference towards older generations and towards traditional life courses in relation to gender roles and workoriented careers was an important part of this process.

As with all hobbies, kosupure brings people together around common interests and allows them to share a common culture. It helps young adults make sense of their lives, recognize and respect difference, and turn a critical eye on the society in which they are reaching adulthood. Kosupure also gives them an opportunity to connect with people they would not otherwise meet, develop a feeling of belonging to a group, and establish mutual respect with other members of their community. This is how cultural citizenship comes into play: these practices allow them not only to identify with popular culture, but also to establish connections with others through these cultural practices, both inside and outside of play. This, in turn, makes it possible for them to create relationships within affinity groups and develop friendships. In this sense, kosupure allows for the establishment of a social space larger than themselves, a space connected to an even larger popular culture that now extends well beyond Japan's borders, through which they enact their cultural citizenship by becoming producers in Japan's cultural industry.

Creating affinity groups is common in Japan and other contemporary societies where, traditionally, relationships linked to immediate and extended family or professional identity have been encouraged. For the young people interviewed, precarious employment and conventional families are at odds with the development of their identity; social insertion is made possible through participation in kosupure. We argue that such practices are one of the vectors by which young adults are able to more fully integrate into Japanese society, a society that is increasingly dependent on cultural citizenship as youths seem to increasingly invest and define themselves through its popular culture and its cultural industry. In fact, high unemployment and precarious, irregular working conditions can no longer support the long-term relationships characteristic of the social order in place until the onset of the economic crisis. Kosupure is the solution these young adults have found to the problem of social isolation, as they claim a right to participate actively in society through their cultural practice and reflexively negotiate the opportunities and constraints that kosupure opens in their life course.

Social insertion through kosupure assumes different forms for each of the three groups identified. On the professional path, practitioners' friendship networks grew through kosupure. The values they share within the kosupure culture create spaces where they feel valued and respected within a larger society that marginalizes them. For practitioners on the enchanted path, costume play creates opportunities to meet people from outside their professional milieu, in which they are well integrated but find somewhat limiting and "boring". For those on the contingency path, kosupure offers "therapeutic" properties by helping them establish new relationships and break out of occasionally "extreme" forms of social isolation. Costume play creates an opportunity to recharge and forget the stress, pressure, and sometimes failures associated with the professional world. For all of the young people interviewed, kosupure created a space where they could challenge or even "break" cultural norms 
enmeshed with social and professional trajectories imposed from outside the kosupure community.

Kosupure also created meaningfulness in young people's life, meanings that changed according to the interplay between their different life trajectories. For some, kosupure represented a new employment market related to the cultural industry that has developed around Japanese popular culture. For others, it was a way to break traditional norms in a career-oriented life course or an opportunity to be socially active in a period of marginalization from the labor market. For professional practitioners in particular, investing in these cultural practices represents a professional investment. Like entrepreneurs, these young adults forge a brand they can "sell" by performing both characters and their identity as professional kosupure practitioners. Often, this means challenging stigmatizing attitudes that still target kosupure and those who practice it.

Having taken much space to present the typology and some of the empirical material on which we based our analyses to illustrate each pathway, we also need to clarify some of the notable limits of this paper. One of the limits of this research is the small sample size in regard to the main interviews. Although participant observation took place over a period of two years and each participant was interviewed three times, it would be interesting to conduct a larger study in order to analyze how these ideal types can be generalized to the entire population of kosupure practitioners, or even to other cultural practices associated with popular culture. It would also be of interest to explore a more traditional longitudinal approach and interview the same participants again in the future, so as to push the analysis further. Given that fieldwork took place in one of Japan's major urban centres, it would also be interesting to study how these pathways develop for young people who grow up and reach adulthood in rural settings. Because the analyses presented here focused on women in particular, a detailed analysis of the specificities pertaining to men's experience would also be of interest to more fully appreciate the place and role of gender in participants' experience. Finally, it would be important to further highlight the Japanese specificities pertaining to each pathway in this typology as well as the distinctiveness of kosupure, namely by engaging more fully with Japanese scholars and scholars working on Japanese leisure more broadly, as well as focusing specifically on the effects of costuming within this practice.

Despite these limits, this study focused on a rarely examined type of citizenship that could facilitate the exploration of a variety of similar practices in Japan and other postindustrial societies. Such research could have political and social consequences, particularly regarding social intervention in the field of social exclusion. In fact, analysis of the role of kosupure in these young people's lives sheds light on both their experiences and the considerable challenges they face. For some, the practice of kosupure is a way of fighting social isolation. It is also a way of struggling against exclusion from the employment market since the beginning of the Lost Decades in the 1990s. For still others, kosupure is a space where practitioners can live and share values different from those of the dominant culture. In this way, participating in these cultural practices further echoes questions of access to cultural citizenship which, as Pakulski (1997) observes, is connected to such issues of marginalization, stigmatization, and assimilation.

Acknowledgments We would like to thank reviewers for their generous and insightful comments during the review process. 
Open Access This article is licensed under a Creative Commons Attribution 4.0 International License, which permits use, sharing, adaptation, distribution and reproduction in any medium or format, as long as you give appropriate credit to the original author(s) and the source, provide a link to the Creative Commons licence, and indicate if changes were made. The images or other third party material in this article are included in the article's Creative Commons licence, unless indicated otherwise in a credit line to the material. If material is not included in the article's Creative Commons licence and your intended use is not permitted by statutory regulation or exceeds the permitted use, you will need to obtain permission directly from the copyright holder. To view a copy of this licence, visit http://creativecommons.org/licenses/by/4.0/.

\section{References}

Arnett, J. J. (2000). Emerging adulthood: A theory of development from the late teens through the twenties. American Psychologist, 55(5), 469-480.

Atkinson, L. (2015). Down the Rabbit Hole: An Exploration of Japanese Lolita Fashion. Thesis. Ottawa: University of Ottawa.

Azuma, H. (2009). Otaku: Japan's Database Animals. Minneapolis \& London: University of Minnesota Press. (Translated by J. E. Abel and S. Kono)

Becker, H. (1963). The outsiders: Studies in the sociology of deviance. Chicago: The Free Press.

Bennett, A. (2018). Conceptualising the relationship between youth, music and DIY careers: A critical overview. Cultural Sociology, 12(2), 140-155.

Brinton, M. (2011). Lost in transition: Youth, work, and instability in postindustrial Japan. Cambridge: Cambridge University Press.

Bucholtz, M. (2002). Youth and cultural practice. Annual Review of Anthropology, 31(1), 525-552.

Campbell, M. (2013). Out of the basement: Youth cultural production in practice and in policy. Montréal: McGill-Queen's University Press.

Caron, C., Raby, R., Mitchell, C., Théwissen-LeBlanc, S., and Prioletta, J.. (2018). How are civic cultures achieved through youth social-change-oriented Vlogging? A Multimodal Case Study. Convergence.

Casemajor, N., Dubé, M., Lafortune, J.-M., and Lamoureux, E.. (2017). Expériences critiques de la médiation culturelle. Québec: Presses de l'Université Laval.

Cohen, A. K. (1955). Delinquent boys: The culture of the gang. Glencoe: The Free Press.

Cohler, B. J., \& Hostetler, A. (2003). Linking life course and life story: Social change and the narrative study of lives over time. In J. T. Mortimer \& M. J. Shanahan (Eds.), Handbook of the life course (pp. 555-578). New York: Kluwer Academic Publishers.

Côté, J. E. (2014). The dangerous myth of emerging adulthood: An evidence-based critique of a flawed developmental theory. Applied Developmental Science, 18(4), 177-188.

Cushman, G., Veal, A. J., and Zuzanek, J., eds. (2005). Free time and leisure participation. International perspectives. Oxfordshire: CABI Publishing.

Daliot-Bul, M. (2009). Asobi in action. Cultural Studies, 23(3), 355-380.

Demazière, D., and Dubar, C.. (2004). Analyser les entretiens biographiques. L'exemple de récits d'insertion. Québec : Presses de l'Université Laval.

Dubar, C. (1998). Trajectoires sociales et formes identitaires, Clarifications conceptuelles et méthodologiques. Sociétés Contemporaines, 29(1), 73-85.

Dupuis, S. L., \& Alzheimer, M. (2008). Leisure and ageing well. World Leisure Journal, 50(2), 91-107.

Elder, G. H. (1985). Perspectives on the life course. In G. H. Elder (Ed.), Life course dynamics: Trajectories and transitions, 1968-1980 (pp. 23-49). Ithaca: Cornell University Press.

Elder, G. H., Kirkpatrick Johnson, M., \& Crosnoe, R. (2003). The emergence and development of life course theory. In J. T. Mortimer \& M. J. Shanahan (Eds.), Handbook of the life course (pp. 3-19). New York: Kluwer Academic Publishers.

Gagné, I. (2008). Urban princesses: Performance and "Women's language” in Japan's gothic/Lolita subculture. Journal of Linguistic Anthropology, 18(1), 130-150.

Gagné, I. (2013). Bracketed Adolescence: Unpacking Gender and Youth Subjectivity through Subcultural Fashion in Late-Capitalist Japan. Intersections: Gender and Sexuality in Asia and the Pacific, 32.

Galan, C. (2018). From youth to non-adulthood in Japan. In P. Heinrich \& C. Galan (Eds.), Being Young in Super-Aging Japan (pp. 32-50). London: Routledge.

Galbraith, P. (2009). The otaku encyclopedia. Tokyo: Kodansha International. 
Gaudet, S. (2007). Emerging adulthood a new stage in the life course: Implications for policy development: Discussion paper. Ottawa: Policy Research Initiative.

Gaudet, S. (2013). "Comprendre les parcours de vie à la croisée du singulier et de la structure sociale.” In Repenser la famille et ses transitions repenser les politiques publiques, edited by Gaudet, S., Burlone, N. and Lévesque, M., 15-50. Presses de 1'Université Laval.

Gaudet, S. and D. Robert. (2018). A journey through qualitative research: From design to reporting. London: Sage.

Genda, Y. (2007). Jobless youths and the NEET problem in Japan. Social Science Japan Journal, 10(1), 2340.

Giddens, A. (1991). Modernity and self-identity: Self and society in the late modern age. Stanford: Stanford University Press.

Gin, J. (2011). Queer simulation: The practice, performance and pleasure of cosplay. Continuum: Journal of Media \& Cultural Studies, 25(4), 583-593.

Gordon, A. (2015). Making sense of the lost decades. In E. Japan's (Ed.), Lost Decades, edited by Yoichi Funabashi and Barak Kushner (pp. 77-100). London: Routledge.

Hall, S., and Jefferson, T., eds. (1976). Resistance through rituals youth subcultures in post-war Britain. London: Routledge.

Hebdige, D. (1979). Subculture. The meaning of style. London: Routledge.

Hodkinson, P. (2012). Beyond spectacular specifics in the study of youth (sub)cultures. Journal of Youth Studies, 15(5), 557-572.

Inui, A. (2003). Restructuring youth: Recent problems of Japanese youth and its contextual origin. Journal of Youth Studies, 6(2), 219-233.

Ito, K., \& Crutcher, P. A. (2014). Popular mass entertainment in Japan: Manga, pachinko, and Cosplay. Society, 51(1), 44-48.

Kelts, R. (2006). Japanamerica: How Japanese pop culture has invaded the U.S.. New York: Palgrave Macmillan.

Kiraya, T., \& Rosenbaum, J. E. (2003). Stratified incentives and life course behaviors. In J. T. Mortimer \& M. J. Shanahan (Eds.), Handbook of the life course (pp. 51-78). New York: Kluwer Academic/Plenum Publishers.

Kuttner, P. J. (2015). Educating for cultural citizenship: Reframing the goals of arts education. Curriculum Inquiry, 45(1), 69-92.

Lamerichs, N. (2011). Stranger than fiction. Transformative Works and Cultures. 7.

Lamerichs, N. (2013). The cultural dynamics of Doujinshi and Cosplay: Local anime fandom in Japan, USA and Europe Participations. Journal of Audience \& Reception Studies, 10(1), 154-176.

Leng, R. (2013). Gender, sexuality, and Cosplay: A case study of male-to-female Crossplay. The Phoenix Papers, 1, 89-110.

Manzenreiter, W., \& Horne, J. (2006). Leisure and Consumer Culture in Japan. Leisure Studies, 25(4), 411415.

Miller, T. (2007). Cultural citizenship: Cosmopolitanism, consumerism, and Television in a Neoliberal age. Philadelphia: Temple University Press.

Miyadai, S. (2011). Transformation of semantics in the history of Japanese subcultures since 1992. Mechademia, 6, 231-258.

Muggleton, D. (2000). Inside subculture: The postmodern meaning of style. Oxford: Berg.

Nomaguchi, K. M. (2006). Time of One's own. Employment, leisure, and delayed transition to motherhood in Japan. Journal of Family Issues, 27(12), 1668-1700.

Oinonen, E. (2018). Under pressure to become - From a student to entrepreneurial self. Journal of Youth Studies, 21(10), 1344-1360.

Okabe, D. (2012). Cosplay, learning, and cultural practice. In M. Ito, D. Okabe, \& I. Tsuji (Eds.), Fandom Unbound: Otaku Culture in a Connected World (pp. 225-258). New Haven, CT: Yale University Press.

Pakulski, J. (1997). Cultural citizenship. Citizenship Studies, 1(1), 73-86.

Pallas, A. M. (2003). Educational transitions, trajectories, and pathways. In J. T. Mortimer \& M. J. Shanahan (Eds.), Handbook of the life course (pp. 165-184). New York: Kluwer Academic Publishers.

Poirier, C. (2013). Politics, identity and the economy in Quebec cinema: Film narratives and the movie industry. In T. Nieguth (Ed.), The politics of popular culture (pp. 131-146). Montréal-Kingston: McGillQueen's University Press.

Rahman, O., Wing-Sun, L., \& Hei-man Cheung, B. (2012). "Cosplay": Imaginative self and performing identity. Fashion Theory The Journal of Dress, Body and Culture, 16(3), 317-341.

Scott, S. (2015). "Cosplay is serious business": Gendering material fan labor on heroes of Cosplay. Cinema Journal, 54(3), 146-154. 
Skeggs, B. (2004). Class, self, culture. London and New York: Routledge.

Stebbins, R. A. (1992). Amateurs, professionals and serious leisure. Montréal: McGill-Queens University Press.

Stevenson, N. (2003). Cultural citizenship: Cosmopolitan questions. Maidenhead: Open University Press.

Stevenson, N. (1997). Globalization, National Cultures and cultural citizenship. The Sociological Quarterly, $38(1), 41-66$.

Suzuki, M. (2007). Gothic, Lolita, visual-Kei: First Kansai then the world (via Harajuku). In Style Deficit Disorder: Harajuku Street Fashion, edited by Godoy, T., 134-165. Goliga books.

Thomson, R., \& Holland, J. (2003). Hindsight, foresight and insight: The challenges of longitudinal qualitative research. International Journal of Social Research Methodology, 6(3), 233-244.

Thomson, R., \& McLeod, J. (2015). New Frontiers in qualitative longitudinal research: An agenda for research. International Journal of Social Research Methodology, 18(3), 243-250.

Thorn, (2004). Girls and women getting out of hand. In Fanning the flames, edited by Kelly, W., 169-187. New York: SUNY Press.

Thornton, S. (1995). Club Cultures: Music, Media and Subcultural Capital. Hanover: University Press of New England.

Threadgold, S. (2018). Creativity, Precarity and Illusio: DIY cultures and "choosing poverty". Cultural Sociology, 12(2), 156-173.

Truong, A. H. (2013). Framing Cosplay: How 'layers' negotiate body and subjective experience through play. Intersections: Gender and Sexuality in Asia and the Pacific. 32.

Truong, A. H. (2016). Kosupure et construction identitaire : La place et le rôle de la culture populaire dans la vie des jeunes Japonais-es (Unpublished doctoral dissertation). University of Ottawa, Ottawa, Canada.

Truong, A. H. And Gaudet, S. (forthcoming). Chapitre IX. Combiner récits et observations: Apports méthodologiques. In Parler de soi, edited by CollectiF.B.. Paris: Éditions de l'EHESS.

Turner, B. S. (2001). Outline of a general theory of cultural citizenship. In N. Stevenson (Ed.), Culture and citizenship culture and citizenship (pp. 11-32). London: SAGE Publications Ltd..

Uchida, Y., and Norasakkunkit, V.. (2015). The NEET and Hikikomori Spectrum: Assessing the risks and consequences of becoming culturally marginalized. Frontiers in Psychology 6.

Voce, A. (2015). The state of Playwork. International Journal of Play, 4(3), 217-223.

White, M. (1993). The material child. Berkeley: University of California Press.

Williams, J. P. (2011). Subcultural theory: Traditions and concepts. Cambridge: Polity Press.

Winge. (2006). Costuming the imagination: Origins of anime and manga Cosplay. Mechademia, 1, 65-77.

Yoda, T. (2006). A roadmap to millennial Japan. In T. Yoda \& H. Harootunian (Eds.), Japan After Japan (pp. 16-52). Durham \& London: Duke University Press.

Publisher's Note Springer Nature remains neutral with regard to jurisdictional claims in published maps and institutional affiliations. 